\title{
Evaluation of cell factory performance through determination of intracellular metabolites using LC-MS/MS
}

Magdenoska, Olivera; Martinussen, Jan; Nielsen, Kristian Fog; Thykær, Jette

Published in:

New Biotechnology

Link to article, DOI:

10.1016/j.nbt.2012.08.413

Publication date:

2012

Document Version

Peer reviewed version

Link back to DTU Orbit

Citation (APA):

Magdenoska, O., Martinussen, J., Nielsen, K. F., \& Thykær, J. (2012). Evaluation of cell factory performance through determination of intracellular metabolites using LC-MS/MS. New Biotechnology, $29 S$.

https://doi.org/10.1016/..nbt.2012.08.413

\section{General rights}

Copyright and moral rights for the publications made accessible in the public portal are retained by the authors and/or other copyright owners and it is a condition of accessing publications that users recognise and abide by the legal requirements associated with these rights.

- Users may download and print one copy of any publication from the public portal for the purpose of private study or research.

- You may not further distribute the material or use it for any profit-making activity or commercial gain

- You may freely distribute the URL identifying the publication in the public portal 
might be viewed as a predisposing factor towards stress-induced pathologies.

http://dx.doi.org/10.1016/j.nbt.2012.08.412

Poster 4.2.16

Evaluation of cell factory performance through determination of intracellular metabolites using LC-MS/MS

Olivera Magdenoska*, Jan Martinussen, Kristian Fog Nielsen, Jette Thykaer

Department of Systems Biology, Denmark Technical University, Kongens Lyngby, Denmark

A major objective in biotechnology is the improvement of the efficiency of host microorganisms used as cell factories. Engineering a strain capable of producing high amounts of a desired biochemical is a multi-step process consisting of design, construction, and analysis of the constructed cell factory. In order to address the function or disfunction of the engineered cells, systems biology tools are employed by using the multi "omics" approach (genomics, transcriptomics, proteomics, metabolomics and fluxomics). Metabolomics is a tool aimed at a quantitative understanding of metabolism. By quantification of intracellular metabolite changes over time, under given genetic and environmental perturbations, key regulatory nodes may be identified in the cellular metabolic network. In target metabolome analysis, the quantification is applied to only one or a small group of metabolites and is very useful for studying the effect of a genetic modification. The approach of targeted metabolomics was applied for the analysis of metabolite extracts from Saccharomyces cerevisiae and Lacctococus lactis. The analytical technique employed was ion-pair liquid chromatography tandem mass spectrometry (LC-MS/MS). The unique combination of sensitivity and specificity of this technique allowed qualitative and quantitative analysis of low metabolite concentrations. The mains steps involved were: (i) metabolite sample preparation by quenching, extraction, sample purification using dispersive Solid Phase Extraction; (ii) quantitative analysis, (iii) data analysis and interpretation. The established analytical method covers analysis of sixty metabolites from glycolysis, cofactors, coenzymes and nucleotides. Implementation of this method provides a powerful new tool in future cell factory design and characterization.

http://dx.doi.org/10.1016/j.nbt.2012.08.413

Poster 4.2.17

Evaluating the effects of clustering methods in coexpression-based functional inference in Arabidopsis thaliana

Sahra Uygun ${ }^{1, *}$, Shin-Han Shiu ${ }^{1,2}$

${ }^{1}$ Genetics Program, Michigan State University, MI 48824, USA

${ }^{2}$ Department of Plant Biology, Michigan State University, MI 48824, USA

Gene co-expression analysis has been widely used for hypothesizing gene functional relations. This is because genes with similar expression patterns are more likely to have similar regulatory mechanisms and, therefore, similar functions. In the model plant Arabidopsis thaliana genome, there are still genes that have no experimentally verified functions. Thus functional inference based on co-expression can be particularly useful for predicting unknown gene functions. In this study, our first goal is to assess how expression data clustering methods as well as input data may influence functional inference of $A$. thaliana genes based on coexpression. In addition, we would like to address the question of whether functions of genes in certain biological processes may be better predicted with the expression data. Different variables in clustering analysis are considered including input expression data, clustering algorithm, distance measure, number of clusters, and functional classification datasets for evaluating the performance in co-expression based functional predictions. Publicly available $A$. thaliana stress expression data is used in the analyses, along with the mostly used partitioning and hierarchical clustering algorithms. During the meeting, we will present how different variable combinations for clustering influence functional prediction accuracy. In addition, we will report whether the prediction performance differ between genes in different functional categories. This work will be useful for evaluating if expression data clustering methods can be optimized for functional prediction and for maximizing the benefits in obtaining biologically meaningful information from gene expression.

http://dx.doi.org/10.1016/j.nbt.2012.08.414

\section{Poster 4.2.18}

\section{A Comprehensive Protein Interaction Network of Cal- cium Triggered Mechanisms in $\mathbf{S}$. cerevisiae}

Senem Tiveci Delikanli*, Türkan Haliloğlu, Kutlu ÖZERGİN Ülgen

Department of Chemical Engineering - Boğaziçi University, İstanbul, Turkey

Calcium, as a common second messenger in eukaryotic cells, plays a vital role in many signaling mechanisms by controlling an extensive variety of cellular processes. This work embodies the first attempt to discover protein interaction network for Calcium triggered mechanisms in S. cerevisiae by utilizing computational methods that integrate interactome data with Gene Ontology. Starting with 12 core proteins, a scale-free network mainly responsible for cell cycle and regulation of transcription is reconstructed. Besides investigating topological features of the network, for the proteins being present in the network but having no known/reported function, a function annotation strategy is applied which enabled to assign a functional role for some of these proteins. Moreover, the linear network decomposition analysis affords assistance to decipher the unknown components of documented pathways e.g. High Osmolarity Glycerol (HOG) and Cell Wall Integrity (CWI) and the crosstalks among them via calcium signaling. Eventually, this work aids to depict a global picture of calcium signaling and its ultimate effects in yeast which may serve as the basis for further studies in higher eukaryotes and lead to a better comprehension of the biological meanings behind them.

http://dx.doi.org/10.1016/j.nbt.2012.08.415 